\title{
MANOLITO GAFOTAS EN ITALIANO. REFLEXIONES SOBRE DOS TRADUCCIONES DIFERENTES DE LA PRIMERA NOVELA DE LA SERIE
}

\author{
MANOLITO GAFOTAS IN ITALIAN. CONSIDERATIONS ON TWO DIFFERENT \\ TRANSLATIONS OF THE SERIES' FIRST NOVEL
}

\author{
MANOLITO GAFOTAS EM ITALIANO. REFLEXÕES SOBRE DUAS \\ TRADUÇÕES DIFERENTES DO PRIMEIRO ROMANCE DA SÉRIE
}

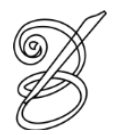 \\ Mercedes ARIZA* \\ Fondazione Universitaria San Pellegrino, Italia
}

\begin{abstract}
Resumen: El presente trabajo pretende analizar la retraducción al italiano de Manolito Gafotas (1994), la novela que inaugura la serie escrita por Elvira Lindo. En 1999 la editorial Mondadori publicó la primera traducción llevada a cabo por Fiammetta Biancatelli, de la que ya se han ocupado algunos expertos (Chierichetti, 2004, 2005; Pérez Vicente, 2015, 2016; Pérez Vicente et al., 2016). Sin embargo, poco se ha escrito sobre la traducción de 2014 realizada por Luisa Mattia y publicada por la editorial Lapis. En particular, nos centraremos en el andamiaje paratextual de esta obra para poner de manifiesto la importancia de las imágenes y de las ilustraciones no solo dentro del texto traducido sino también, y de manera especial, en todos los elementos que lo rodean.

Palabras clave: Traducción. Literatura infantil y juvenil. Paratexto. Doble destinatario.
\end{abstract}

Abstract: The aim of the present paper is to analyse the Italian retranslation of Manolito Gafotas (1994), the Spanish novel which inaugurates the series written by the Spanish journalist and novelist Elvira Lindo. In 1999, the publishing company Mondadori published the first translation carried out by Fiammetta Biancatelli, that has already been analysed by some experts (Chierichetti, 2004, 2005; Pérez Vicente, 2015, 2016; Pérez Vicente et al., 2016). However, there are few studies about the translation of 2014 carried out by Luisa Mattia and published by the publishing company Lapis. In particular, we will focus on the paratextual framework of this novel in order to highlight the importance of images and illustrations, not only within the translated text, but also, and especially, within the elements that surround it.

Keywords: Translation. Children's Literature. Paratextual Elements. Double Audience.

Resumo: O presente artigo pretende analisar a retradução, para o italiano, de Manolito Gafotas (1994), o romance que inaugura a série escrita por Elvira Lindo. Em 1999, a editora Mondadori publicou a primeira tradução realizada por Fiammetta Biancatelli, da qual se ocuparam alguns especialistas (Chierichetti, 2004, 2005; Pérez Vicente, 2015, 2016; Pérez Vicente et al., 2016). Contudo, pouco se escreveu sobre a tradução de 2014, realizada por Luisa Mattia e publicada pela editora Lapis. Em particular, nos concentraremos sobre o aparato paratextual desta obra a fim de trazer à luz a importância das imagens e das ilustrações não apenas dentro do texto traduzido, mas também, e de modo especial, em todos os elementos que o rodeiam.

Palavras-chave: Tradução. Literatura infantil e juvenil. Paratexto. Duplo destinatário.

Recebido em: 24 de setembro de 2018

Aceito em: 04 de maio de 2019

Publicado em: julho 2019

ARIZA, Mercedes. Manolito Gafotas en italiano. Reflexiones sobre dos traducciones diferentes de la primera novela de la serie. Belas Infiéis, Brasília, v. 8, n. 3, p. 37-58, 2019. 


\section{Introducción}

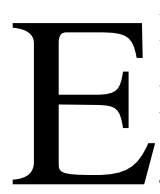

1 punto de partida del presente trabajo es nuestra participación en el XI Congreso Internacional de la Asociación Nacional de Investigación en Literatura Infantil y Juvenil (ANILIJ) que tuvo lugar en la Universidad de Granada (España) del 27 al 29 de septiembre de 2017. El objetivo de nuestra ponencia: "Manolito Gafotas en italiano. Reflexiones sobre el andamiaje paratextual de la traducción al italiano de 2014”, era presentar un análisis descriptivo y crítico de la traducción italiana publicada en 2014 por la editorial Lapis. En particular, se intentó poner de manifiesto el fenómeno de la retraducción en el ámbito literario, puesto que la traducción de 2014 se sumaba a la primera traducción de Manolito publicada por Mondadori. Dicha traducción llevada a cabo en 1999 por Fiammetta Biancatelli, con ilustraciones originales de Emilio Urberuaga, ya ha sido objeto de estudio (CHIERICHETTI, 2004, 2005; PÉREZ VICENTE, 2015, 2016; PÉREZ VICENTE et al., 2016).

En 2014, exactamente veinte años después de la publicación del original en español, y con motivo de la Feria del libro de Bolonia ${ }^{1}$, la editorial Lapis presentó una nueva traducción bajo el título Ecco Manolito y realizada por Luisa Mattia, siempre con las ilustraciones originales de Urberuaga ${ }^{2}$.

Nuestro trabajo se propone reflexionar acerca de las dos traducciones llevadas a cabo en general y en los aspectos inherentes a su andamiaje paratextual en particular. De hecho, intentaremos hacer hincapié en la importancia de las imágenes y de las ilustraciones no solo en el texto traducido sino también, y de manera especial, en todos aquellos elementos que lo rodean como, por ejemplo, la portada, la controportada, el catálogo, las presentaciones del libro en general que constituyen el llamado paratexto (GENETTE, 1987).

Nuestro análisis se enmarca en la confluencia de dos líneas de investigación principales, esto es, la traducción de la literatura infantil y juvenil (en adelante, TradLIJ) (OITTINEN, 2000; PASCUA et al., 2003; RUZICKA y LORENZO, 2003; RUZICKA, 2008, 2009; DI GIOVANNI et al., 2010; PEDERZOLI, 2012; LEFEBVRE, 2013; BAZZOCCHI y TONIN, 2015) y la traducción de los elementos paratextuales (ELEFANTE, 2012; GIL-BARDAJÍ et al., 2012; MÉNDEZ, 2015; YUSTE, 2007, 2012). 


\section{Manolito Gafotas en italiano}

\subsection{La traducción de Mondadori de 1999}

En 1999, precisamente cinco años después de la publicación de la novela que inaugura la serie, la editorial Mondadori publicó Manolito Quattrocchi traducida por Fiammetta Biancatelli y con las ilustraciones originales de Emilio Urberuaga. Es oportuno recordar que esta entrega reunía las dos primeras novelas de la serie (Manolito Gafotas y Pobre Manolito), lo que se reveló, para algunos, una decisión editorial discutible (CHIERICHETTI, 2004). De hecho, no resultaba apropiado ni ameno proponer un tomo de más de doscientos páginas en lugar de dos volúmenes más ágiles de leer por separado.

Entre las tantas definiciones y consideraciones sobre Manolito, nos gusta presentarlo “como un cronista de la sociedad en la que vive" (ÁLVAREZ y SOLIÑO, 2003, p. 60), puesto que relata de manera realista y humilde lo que pasa a su alrededor. Estamos pues ante un "niño testigo que da una perspectiva nueva del mundo que todos conocemos" (ÁLVAREZ y SOLIÑO, 2003, p. 60), en la que afloran temas cercanos a la vida de un niño como la amistad, la relación familiar, la escuela, todo esto a través de las gafas de un niño de los años 90 que vive en la periferia de Madrid. Por otra parte, las aventuras de Manolito son aventuras reales de su día a día: comprar un cuerno para su trenca, subir al camión de su padre, viajar en metro con su abuelo o ir al museo con sus compañeros (PÉREZ DÍEZ, 2003).

Con respecto a la edición española de Alfaguara, dirigida a jóvenes de 12 años de edad, la traducción de 1999 está ubicada en la colección Junior -10 de Mondadori. Este cambio etario, según Chierichetti (2004), justifica la 'neutralización', por no decir 'purificación' de muchos aspectos lingüísticos y culturales. De hecho, este tipo de intervencionismo no solo refleja una actitud paternalista del traductor (LORENZO, 2014), sino cumple también con meras cuestiones comerciales de la editorial. A finales de los años noventa ciertos temas se consideraban poco apropiados para los niños y, por esta razón, se eliminaban por completo las alusiones a la muerte y a la violencia física, por ejemplo. En concreto, la traducción de Mondadori de 1999 refleja un alto nivel de censura en cuanto a comportamientos, costumbres y maneras de ser de los personajes. Por otra parte, son varios ya los estudios que ponen de manifiesto la actitud censora de los traductores (o quien por ellos) sobre todo en las traducciones al inglés estadounidense, donde se hace caso omiso de la afición del abuelo por el tinto de verano (CÁMARA, 2016; MARCELO, 2016; ALDERETE y HARRINGTON, 2017). Es más, la misma Elvira Lindo explicó por qué aceptó 'la versión light' de Manolito, diciendo que. “el problema de la corrección política ha llevado a que las collejas desaparezcan, y otros detalles, 
como que el que Manolito dé un trozo de chocolate a su perro es considerado maltrato animal" (Exlibris, 2008). Esta versión 'descafeinada' ha permitido cumplir con la moral imperante en la cultura meta $(\mathrm{CM})$ y ha hecho posible llevar las peripecias de Manolito allende el Atlántico.

Por otra parte, nos encontramos ante un libro para niños que ha sido escrito por un adulto. Según recuerda Pérez Díez (2003, p. 471): “al leer sus confesiones autobiográficas parece como si por primera vez estuviésemos descubriendo a los niños que un día fuimos". Por ello consideramos que se trata de un libro de doble destinatario, dirigido a los niños en general y leído, al mismo tiempo, por los adultos.

Volviendo a la traducción italiana de 1999, destacan en ella un interés excesivamente explicativo o un afán sintetizador en cuanto al trasvase de las etiquetas lingüísticas, la eliminación de ciertas expresiones completas o el recurso al uso de eufemismos para cumplir con las normas de aceptabilidad en la CM, por lo que se refiere al tratamiento del lenguaje soez, y un exceso de literalidad sobre todo en el caso de las unidades fraseológicas desautomatizadas que reflejan los errores típicos del habla infantil (ARIZA, 2017)3․ Por su parte, Pérez Vicente (2016) hace especial hincapié en las dificultades de encasillar las novelas de Manolito dentro 40 del género exclusivamente infantil y, según ella, la clave de lectura de la novela reside en el "lenguaje coloquial y expresivo con el que Manolito, narrador autodiegético, se dirige a un interlocutor ficticio al que trata de tú a tú" (PÉREZ VICENTE, 2016, p. 183).

\subsection{La retraducción de Lapis de 2014}

Antes de abordar la traducción de 2014, cabe reflexionar sobre el concepto de retraducción y sobre sus implicaciones a nivel traductológico, esto es, un ámbito de estudio donde destaca la falta de unanimidad en cuanto al significado concreto de "retraducción" (ZARO y RUIZ, 2007). Sin embargo, para nuestro estudio optamos por la definición de Chaume (2007), donde por retraducción se entienden "las segundas, terceras, cuartas o n-traducciones consecutivas del mismo texto" (CHAUME, 2007, p. 49). Por otra parte, según recuerda el mismo autor, el concepto de retraducción tiene un carácter meramente diacrónico, ya que "dos traducciones simultáneas de un mismo texto a una misma lengua no serían consideradas retraducciones, sino (primeras) traducciones simultáneas" (CHAUME, 2007, p. 49). Según estudios recientes (BERTINETTI, 2013; SICILIANO, 2013), a menudo las retraducciones son totalmente necesarias tanto para rejuvenecer el texto traducido como para corregir errores de interpretación. Y entonces: ¿por qué se ha optado por la retraducción de Manolito? ¿A quién está dirigida esta nueva traducción? ¿Habrá sido necesario actualizar ciertos elementos del 
original? ¿Se han modificado los elementos paratextuales? ¿Qué efectos habrá tenido todo ello en la recepción de las aventuras del niño de Carabanchel? He aquí algunos interrogantes a los que nos gustaría intentar responder, aunque de manera parcial, a través de nuestro estudio.

En marzo de 2014 se publicó la nueva traducción de Manolito con el título Ecco Manolito (lit. Aquí está Manolito). Dicha traducción, llevada a cabo por Luisa Mattia y editada por Lapis, se presentó con motivo de la Feria del libro de Bolonia de 2014. Según explica Rosaria Punzi, la responsable del proyecto editorial, fue un verdadero placer presentar al público italiano un personaje tan actual como Manolito, que, a través de su ingenuidad e ironía, describe la sociedad que nos rodea (MINARDI, 2014). Por su parte, Luisa Mattia explica que, aun no siendo una traductora profesional, ha sostenido con dignidad el reto, puesto que "hacía falta una escritora para rendirle justicia a la escritora del texto original" (MINARDI, 2014). En conclusión, una vez más, nos encontramos ante una cuestión espinosa: para traducir literatura en general y textos de LIJ en particular, ¿es necesario ser escritor?, ¿el traductor, qué función desempeña?, ¿él mismo no es, a su vez, un escritor?, ¿no es el autor de la traducción final?

\subsubsection{La traductora italiana: Luisa Mattia}

Como adelantábamos, Luisa Mattia no es una traductora profesional, sino una autora reconocida de libros para niños ${ }^{4}$. Su experiencia en el mundo editorial italiano se desprende de su colaboración con numerosas editoriales de Italia; además es guionista para dibujos animados y series televisivas que se transmiten en la cadena televisiva estatal (RAI). Participa en Festivales de literatura para niños, así como en talleres y propuestas de animación a la lectura para niños de diferentes edades. En una entrevista radiofónica de 2014, Mattia explica que lo más importante a la hora de traducir la novela de Elvira Lindo fue "buscar la lengua de la calle", la misma calle por donde transitan Manolito y su abuelo, sus compañeros del colegio y otros personajes. Por otra parte, alrededor de nuestro protagonista existe un barrio, una cárcel, una clase social definida, una humanidad con problemas concretos (MATTIA, 2014). Sin embargo, según la misma traductora, hay algo que va más allá de lo cotidiano: Manolito tiene una gran capacidad para aislarse, decodificar la realidad y describir su "mundo mundial". Manolito es un vencedor, no respeta las reglas pero es un niño bueno y sincero. El mayor desafío, como adelantábamos, fue respetar el ritmo de una lengua seca, popular, material (MATTIA, 2014). Según explica Mattia, su objetivo principal fue afinar el habla de Manolito para no perder su eficacia comunicativa. Por otra parte, no debemos olvidar que las peripecias del protagonista 
tienen lugar en los años 90 del siglo XX, en una España posfranquista, muy animada, experimental y con un lenguaje por fin libre (MATTIA, 2014).

\title{
2 Traducción y paratraducción
}

El término paratraducción, acuñado por el grupo de investigación "Traducción \& Paratraducción" de la Universidad de Vigo, encierra un concepto muy amplio y novedoso, esto es, analizar el impacto estético, político, ideológico y cultural así como las manipulaciones sociales que se desprenden del andamiaje paratextual de todo tipo de texto (GIL-BARDAJÍ $e t$ al., 2012). En otras palabras y como veremos más adelante:

\begin{abstract}
si un texto no puede existir sin paratexto, una traducción tampoco puede existir sin su correspondiente paratraducción, ya que esta no solo introduce y presenta la traducción sino que la acompaña, rodea, envuelve y prolonga como tal en la lengua y cultura de llegada, posibilitando la existencia de la traducción en el mundo editorial ya sea en papel o en pantalla. (MÉNDEZ, 2015, p. 88)
\end{abstract}

Por otra parte, el objetivo principal es subrayar el papel determinante que desempeñan todos los elementos paratextuales a lo largo del proceso de traducción, o mejor dicho, de paratraducción (YUSTE, 2007, 2012; ELEFANTE, 2012; MÉNDEZ, 2015) ${ }^{5}$.

\subsection{El papel del traductor paratextual}

Yuste (2007) reflexiona sobre la necesidad por parte del traductor de leer e interpretar correctamente cada uno de los elementos textuales y paratextuales subyacentes al imaginario de la obra que se traduce. Desde luego, no solo se traducen las palabras y el texto verbal en su conjunto, sino también las imágenes, los sonidos, los movimientos y hasta los sabores que se desprenden de una obra. En definitiva, "el traductor traduce texto y paratraduce paratextos" (YUSTE, 2007, p. 135). Dichas consideraciones son de suma relevancia en el caso que nos ocupa, ya que también en Manolito, las imágenes complementan las palabras y son un soporte visual que respalda la narración de tipo verbal; tienen, pues, un carácter ilustrativo realista. Por otra parte, las ilustraciones de Emilio Urberuaga se convierten en un componente indispensable para comprender las peripecias del niño de Carabanchel. Al respecto, el traductor deberá ser consciente de esto, puesto que a menudo la editorial del TM interviene en los aspectos paratextuales, emprobreciendo la lectura e interpretación de las estructuras simbólicas presentes en el TO (YUSTE, 2012). Dicha intervención, tal y como recuerda el mismo autor, no es nada casual: la edición de los elementos paratextuales traducidos ocultan implicaciones de tipo ideológico, social y cultural (YUSTE, 2012, p. 132). 


\subsection{Definición y características del paratexto}

Retomando la definición ya célebre de Genette (1987), podemos considerar el paratexto como el conjunto de aquellos elementos que se sitúan en la periferia del texto literario propiamente dicho. En particular, está formado por dos componentes principales: el peritexto y el epitexto cuyos elementos son de suma importancia, ya que pueden influir de manera determinante en la aceptación y/o inclusión de un determinado texto en la cultura meta (YUSTE, 2007; ELEFANTE, 2012; ELEFANTE y PEDERZOLI, 2015). De hecho, incluso las editoriales pueden manipular los componentes paratextuales presentes en las obras de LIJ con un afán censor para cumplir con la moral y/o determinadas prácticas sociales de la $\mathrm{CM}$ (ELEFANTE, 2012; GIL-BARDAJÍ et al., 2012).

En el ámbito italiano Elefante y Pederzoli (2015) han llevado a cabo un interesante estudio sobre el tratamiento de los peritextos en las traducciones italianas de un corpus de novelas escritas en francés. En particular, analizan de qué manera las editoriales presentan el tema de la muerte a los destinatarios de las obras traducidas; con respecto a los originales en francés, las autoras notan, por un lado, un gran afán por tranquilizar al adulto sobre la compra del libro en cuestión y, por otro, la tendencia a suavizar, si no eliminar de manera explícita, el tema de la muerte y no herir la supuesta sensibilidad de los más jóvenes ${ }^{6}$. Por otra parte, es, precisamente, a través del paratexto que la editorial redefine el destinatario final de la obra y decide, por ejemplo, si una obra traducida encaja mejor en una colección dirigida a jóvenes, pre-adolescentes o adolescentes (PEDERZOLI, 2012, p. 93). Con ello destaca, una vez más, el papel determinante desempeñado por la editorial a la hora de presentar una obra traducida a los lectores de la CM. En nuestro caso concreto, resultará interesante ver de qué manera se han retraducido los paratextos inherentes a la primera entrega de Manolito, entre otras razones, porque en las últimas décadas no solo ha ido cambiando el papel de las editoriales sino también los criterios de traducción adoptados.

\subsubsection{Definición y características del peritexto}

En el peritexto destacan los siguientes elementos: título, subtítulo, intertítulos, prólogo, epílogo, notas, dedicatorias, advertencias así como todos los aspectos no verbales (la fuente, el tamaño y la forma de la letra y las ilustraciones, por ejemplo) (GENETTE, 1987). A su vez se incluyen la cubierta, el formato, la contracubierta, la colección editorial de referencia y la tirada del libro en cuestión (DEMARIA y FEDRIGA, 2001). En el ámbito de la LIJ, el peritexto está dirigido a dos grupos diferentes de lectores: a los adultos que buscan una legitimación de la 
valía del autor de la obra y a los jóvenes que necesitan ser cautivados en la lectura. En otras palabras, el peritexto editorial se revela como un espacio textual dirigido a múltiples destinatarios: los lectores y los adultos, en tanto que mediadores, revisores o tutores. Si bien es cierto que "toutes les autres parties du livre, notamment la quatrième, le dos et, lorsqu'ils sont présents, les rabats de la jaquette, abritent toute une série de textes intéressants" (PEDERZOLI, 2012, p. 85). La cubierta, por ejemplo, es un texto sincrético por excelencia al tener un gran valor comunicativo y al ser un verdadero espacio de mediación. Por otra parte, en la contracubierta reside la verdadera comercialización del libro porque es precisamente aquí donde queda patente la voluntad de la editorial de capturar la atención del lector y sobre todo de convencerlo para que compre la obra.

Según Elefante y Pederzoli (2015), en el ámbito editorial italiano se pretende legitimar la valía literaria del libro traducido y de su autor a través de la mención de los galardones recibidos, comentarios elogiadores y extractos de reseñas. Dichos elementos, que suelen aparecer en la contracubierta o en las solapas, desempeñan un papel determinante, ya que los adultos necesitan "ser tranquilizados" (ELEFANTE y PEDERZOLI, 2015, p. 73). Por otra

44 parte, todo lo dicho se enmarca en un fenómeno ya conocido en el ámbito editorial internacional y en el campo de la LIJ en particular, a saber, el concepto de doble destinatario o crossover. Desde el ámbito anglosajón, Wall (1991) ha sido uno de las pioneras en analizar lo que se suele llamar 'crossover fiction', haciendo hincapié en la intencionalidad de tipo comercial con la que se conciben los textos literarios dirigidos a niños y jóvenes. En concreto, según esta estudiosa, los adultos tienen que ser atraídos, capturados y estar convencidos de lo que compran para sus hijos; detrás de todo ello, se esconderían evidentes intereses comerciales, puesto que "if books are to be published, marketed and bought, adults first must be attracted, persuaded and convinced" (WALL, 1991, p. 13) 7 .

\subsubsection{Definición y características del epitexto}

El epitexto, lo que está fuera de los límites del texto propiamente dicho, puede ser público o privado. El primero incluye las entrevistas del autor, del traductor y/o del ilustrador, las reseñas, los debates y las presentaciones del libro y el catálogo de la editorial, mientras el segundo abarca las cartas y/o los mensajes escritos por el autor de la obra para un uso privado. Tal y como recuerda Genette (1987), el destinatario del epitexto público no debe necesariamente coincidir con los lectores de la obra, puesto que su carácter público se explica, 
precisamente, a través del hecho de estar dirigido a periodistas, oyentes y participantes en un congreso o mesa redonda, por ejemplo.

Una vez analizado el significado del paratexto y de sus componentes, pasamos a reflexionar sobre otro tema fundamental en el ámbito de la traducción de la LIJ y de la paratraducción en particular: la coherencia entre texto e imagen, puesto que "tanto el texto como la imagen participan en la construcción del mensaje legible y visible complementándose en un movimiento circular reflexivo y creativo al mismo tiempo" (MÉNDEZ, 2015, p. 84).

\subsection{Las ilustraciones}

La estudiosa Oittinen (2003, 2010), desde su experiencia como ilustradora de cuentos no solo en su lengua materna, sino también en las traducciones al inglés, hace hincapié en el aspecto primordial de las ilustraciones y del componente visual en su conjunto. De hecho, es necesario analizar la forma y el tamaño de las letras que pueden acompañar las imágenes u otros aspectos más generales de tipo gráfico como son los encabezamientos, los pies de foto o ilustraciones y cualquier otro recurso de tipo visual que puede decir mucho acerca de los personajes y de la historia. Por otra parte, las ilustraciones pueden dar pistas para descifrar el carácter de algunos protagonistas, puesto que no todo está escrito en las palabras, sino que de hecho algunos rasgos pueden ocultarse únicamente detrás de las imágenes (OITTINEN, 2003). Por su parte, Lorenzo $(2011,2014)$ reflexiona sobre la necesidad de adaptar y/o incluso modificar las imágenes de un texto original (TO) con el objetivo de cumplir con la coherencia temática y visual en el texto meta (TM), puesto que se trata de un factor clave durante el proceso de traducción (LORENZO y PEREIRA, 2000). Asimismo, resulta imprescindible optar por una estrategia traductora que consiga mantener dicha coherencia a lo largo de todo el texto y en la que no se produzcan deslices-despistes.

La relación entre texto e imagen así como el papel determinante desempeñado por el ilustrador permanecen temas aún poco explorados en el ámbito de la LIJ, lo que puede explicar el fracaso editorial de ciertas traducciones (PÉREZ VICENTE et al., 2016). De hecho, tal y como ha ocurrido en el trasvase de Manolito al alemán, el cambio de ilustrador y la poca atención prestada al destinatario de la serie explican el fracaso editorial de las traducciones en este idioma (VALERO, 2016). 


\section{Análisis del andamiaje paratextual en Ecco Manolito (2014)}

Para llevar a cabo nuestro análisis seguiremos el mismo orden establecido en la parte teórica de nuestro estudio. Empezaremos pues por los elementos inherentes al peritexto $(\S 3.1)$, luego focalizaremos nuestra atención en el epitexto (§ 3.2) y en el tratamiento de las ilustraciones y su relación con el texto escrito (§ 3.3). Es oportuno subrayar que la traducción italiana de 2014 se basa en la edición de Seix Barral de $2013^{8}$, puesto que a lo largo de nuestra investigación hemos podido comprobar que las novelas editadas por Alfaguara en los años 90 ya están descatalogadas. Por otra parte, también en español ha tenido lugar un cambio radical en cuanto a edición y maquetación del texto (selección y uso del color, tamaño, tipo y fuente de letra), tal y como salta a la vista a través del cotejo de las cubiertas:

Figura 1 - Cubiertas de las diferentes ediciones

$\begin{array}{cccc}\text { Cubierta de la } 9 \text { edición } & \begin{array}{c}\text { Cubierta de la traducción } \\ \text { de Alfaguara (1996) }\end{array} & \begin{array}{c}\text { Cubierta de la } 16 \text { edición } \\ \text { de Mondadori (1999) }\end{array} & \begin{array}{c}\text { Cubierta de la traducción } \\ \text { de Lapis }(2014)\end{array}\end{array}$
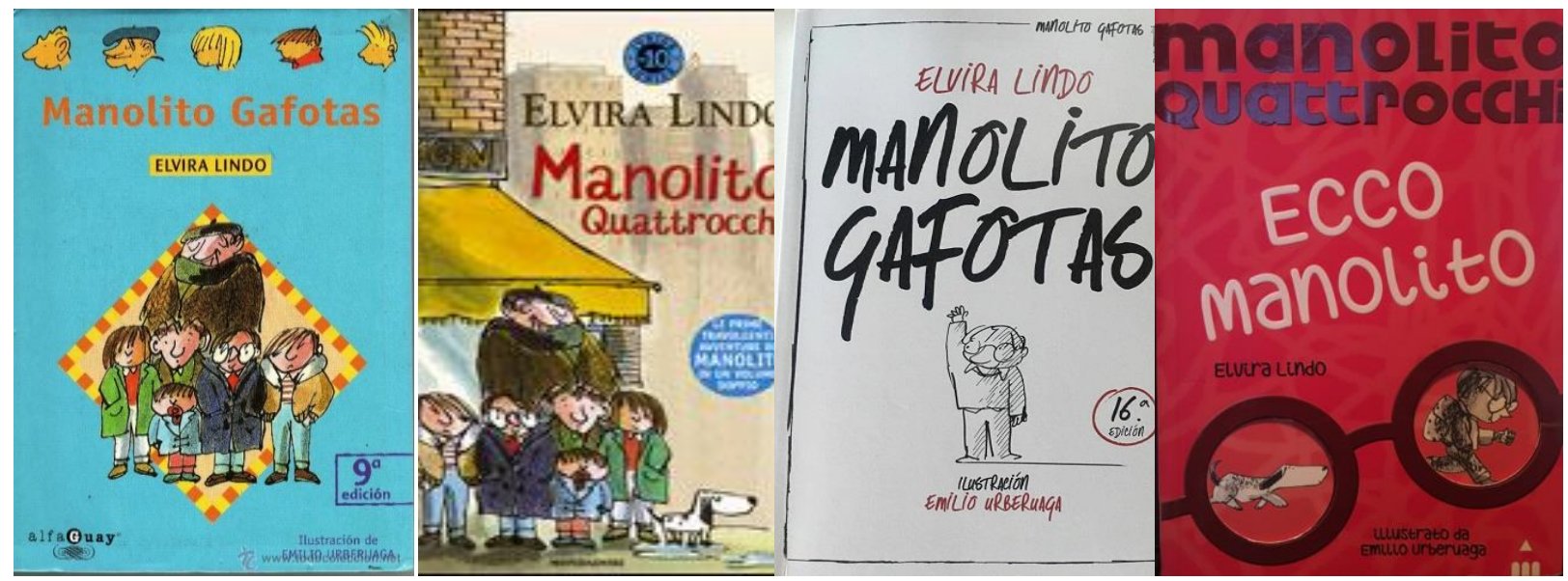

\subsection{Análisis del peritexto: de la cubierta a la contracubierta}

En la cubierta del libro encuentran cabida el título de la obra, los datos del autor, del ilustrador y de la editorial en general. En la traducción de 2014 el formato y la selección de los colores resultan mucho más atractivos; de hecho, el título Ecco Manolito está escrito en blanco y en letra redonda sobre fondo rojo, mientras en la parte superior se puede leer el nombre de la serie Manolito Quattrocchi en negro y en letra de imprenta. Además, siempre en la cubierta se ha optado por insertar las "gafas" de Manolito, un elemento que cautiva la atención del público joven, que puede usar la tapa para "ver" a través de las gafas del protagonista. De esta manera, el lector interviene de manera directa en las aventuras del niño 
y la lectura se transforma en una actividad multisensorial, tal y como se puede ver en la imagen siguiente:

Figura 2 - Análisis de la cubierta

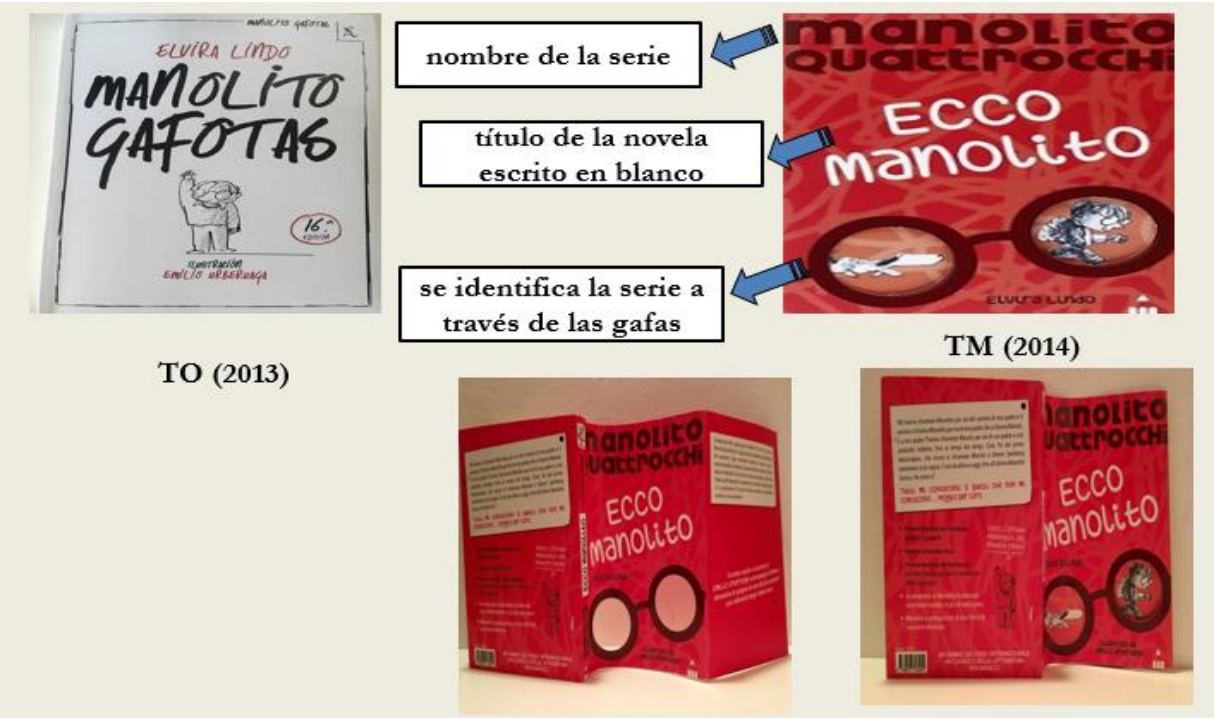

Tal y como adelantábamos, en la contracubierta reside la verdadera comercialización del libro. En la versión italiana se pretende legitimar la valía literaria de la obra, de su autor y de su ilustrador de tres maneras diferentes: en primer lugar, se mencionan los galardones recibidos, esto es, el Premio Nacional de Literatura Infantil y Juvenil, el Premio Cervantes chico y el Premio Nacional de Ilustración otorgado a Emilio Urberuaga por el conjunto de su obra. Es evidente que la mención de dichos galardones cumple con la función comercializadora de la que hablábamos. Asimismo, se hace explícito el hecho de que Manolito se ha traducido en más de veinte países. Por otra parte, se legitima la valía de la obra aclarando que ha sido fuente de inspiración para dos películas y una serie televisiva. Finalmente, la editorial italiana pretende convencer a su lector/comprador potencial explicando que se trata de "un gran successo internazionale e un classico della letteratura per ragazzi” (lit. "un gran éxito internacional y un clásico de la literatura para jóvenes”). En definitiva, la fama internacional de Manolito y su presentación como un clásico de la literatura infantil y juvenil constituyen la mejor tarjeta de presentación de la obra. 
Figura 3 - Análisis de la contracubierta

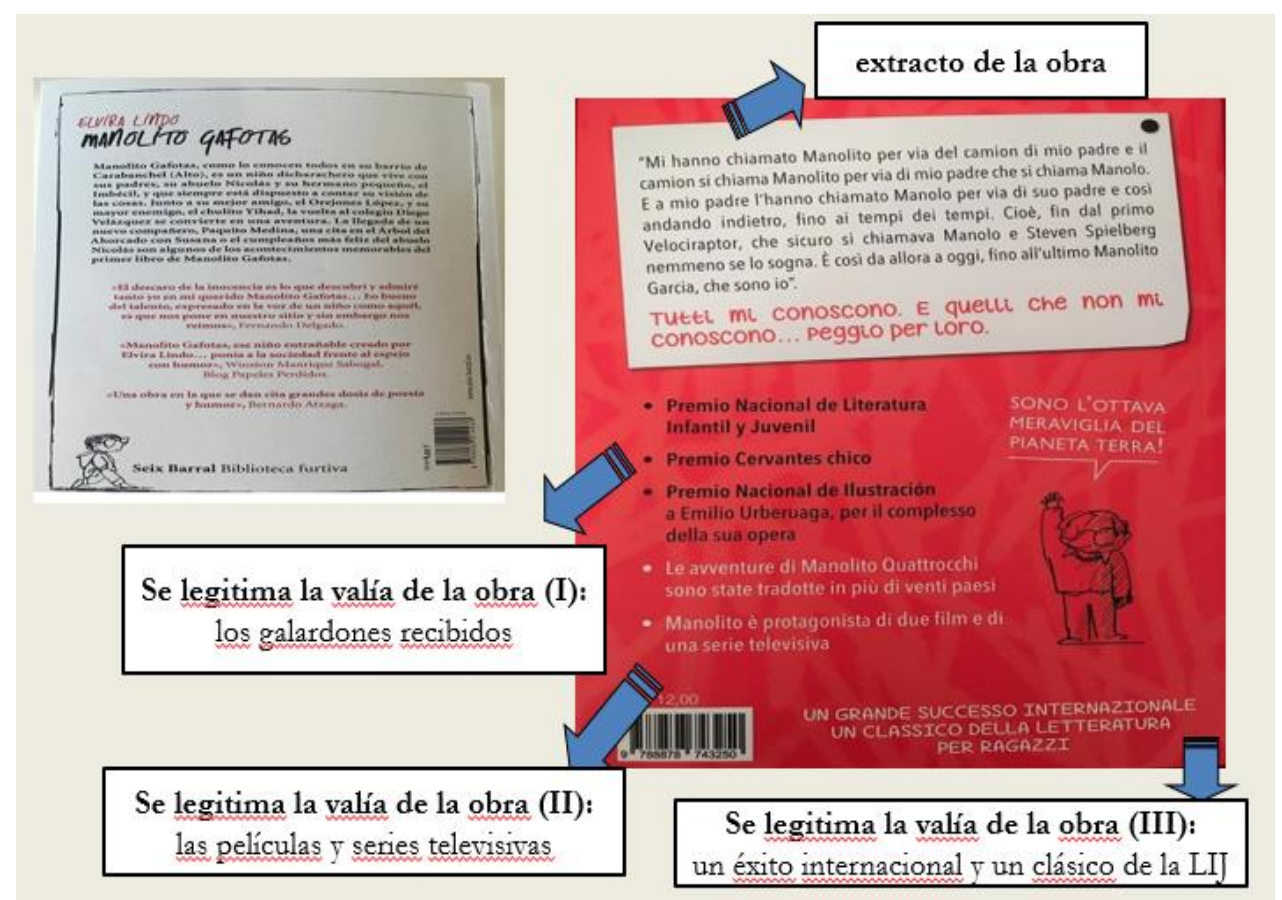

\subsubsection{Otros elementos peritextuales}

En la edición de Seix Barral de 2013 se añaden dos elementos peritextuales inexistentes en la versión editada por Alfaguara de 1994. En particular, se trata de una dedicatoria (a) al comienzo del libro y de una nota de la autora o, mejor dicho, de una advertencia (b) justo después del índice en la parte final del libro. Sería interesante descubrir las razones que han llevado a añadir esta nota final, puesto que en la versión original de 1994 no había surgido la necesidad de justificar ciertos errores gramaticales y otras incorrecciones presentes en el libro.

Tal como sea, ambos elementos se han traducido al pie de la letra en italiano, tal y como se aprecia a continuación:

(a)

TO

Para Antonio Muñoz Molina, mi vida

TM

Per Antonio Muñoz Molina, mia vita

(b)

TO 


\section{NOTA}

Espero que los lectores disculpen los errores gramaticales y otras incorrecciones que aparecen en el libro. Tanto los editores como yo hemos querido ser fieles a la voz del personaje. Puede que, con unos años más dentro del sistema educativo, Manolito supere estos fallos. De momento, entendemos que conforman su personalidad literaria.

\section{TM}

\section{NOTA DELL'AUTRICE}

I lettori perdoneranno errori grammaticali e altre scorrettezze che sono in questo libro. Io e l'editore abbiamo voluto essere fedeli alla voce del personaggio. Continuando ad andare a scuola, può essere che Manolito superi questi problemi. Nel frattempo, gli errori faranno parte della sua personalità letteraria.

\subsection{Análisis del epitexto: de las entrevistas al catálogo de la editorial}

En el ámbito del epitexto público, esto es, el conjunto de aquellos elementos paratextuales que desbordan los límites del libro propiamente dicho, ha sido posible consultar entrevistas y reseñas de prensa sobre la presentación de Manolito en 2014. Por otra parte, existe abundante material escrito, fotográfico y de tipo promocional que atestigua la participación de Elvira Lindo y de la traductora italiana en ferias, festivales de literatura, talleres de animación a la lectura en las escuelas y otras iniciativas por el estilo. Ahora bien, lo que más nos ha llamado la atención ha sido la descripción de la serie de Manolito que podemos leer en la página 37 del catálogo de 2017 de la editorial Lapis. De hecho, precisamente, en esta página se hallan algunos elementos interesantes para nuestro análisis. En primer lugar, aparece la franja de edad que, como adelantábamos, ha cambiado respecto al TO. La editorial Lapis recomienda la lectura de Manolito a partir de 9 años de edad, aunque deja patente que es un libro para "lectores de cualquier edad", lo que hace de Manolito un texto de doble destinatario. Asimismo, el protagonista de la novela se convierte en el héroe que todos estábamos esperando sin restricción de ningún tipo. Finalmente, destaca un guiño intertextual a la serie de Jeff Kinney conocida en italiano como El diario di una schiappa cuyo significado coincide con la segunda parte del título en español (Un pringao total). Queda por descubrir si se trata realmente de un gancho editorial o si, al contrario, como podemos suponer, es una manera para no confundir a Manolito Gafotas con el personaje de Greg. 
Figura 4 - Página 37 del catálogo de 2017 de la editorial Lapis

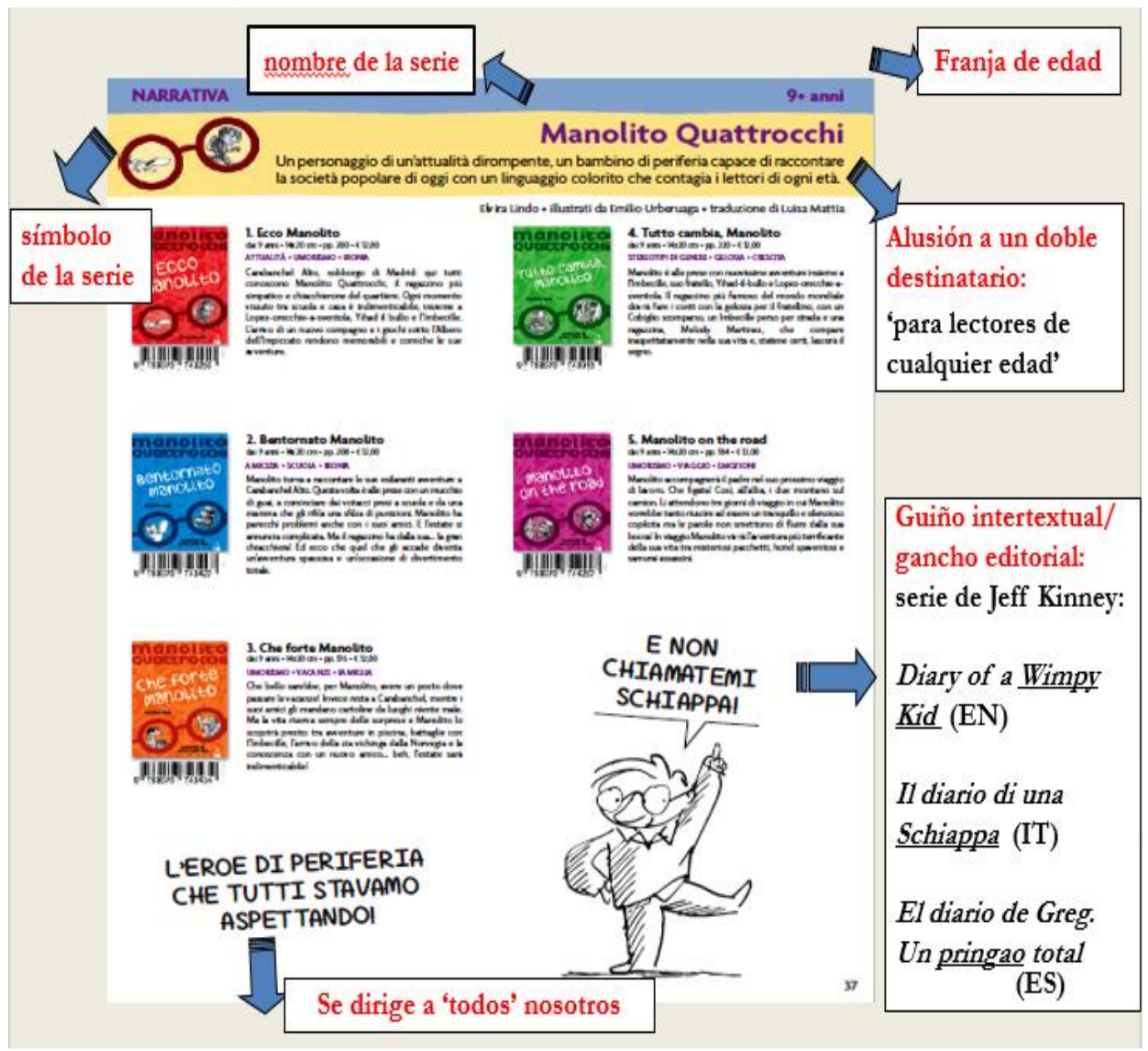

\subsection{Ilustraciones y traducción}

El tratamiento traductológico de las ilustraciones es de suma importancia en Manolito, ya que son un apoyo a la imaginación del lector y son incluidas tras el discurso textual (ÁLVAREZ y SOLIÑO, 2003). De hecho, en la descripción de las aventuras del niño de Carabanchel encuentran cabida algunas imágenes e incluso al principio de cada capítulo hay una pequeña ilustración que resume su contenido. En este apartado intentaremos reflexionar sobre la traducción del componente verbal que acompaña el soporte visual para ver si el título en italiano comparte la misma relación presente en el TO o si se crea algún tipo de incoherencia verbal y visual, debido al cambio del elemento visual sin haber tenido en cuenta el componente textual o viceversa. Además será interesante notar las diferencias en el uso del color, el tamaño y el tipo de letra así como otros aspectos de la edición en su conjunto.

En la traducción italiana de 2014 se traducen, por lo general, todos los elementos textuales que acompañan las imágenes como, por ejemplo, el nombre del camión del padre de 
Manolito (a), el cartel del bar (b) y el título de un cuaderno de notas de Manolito (c), tal y como se desprende de las imágenes siguientes:

a)

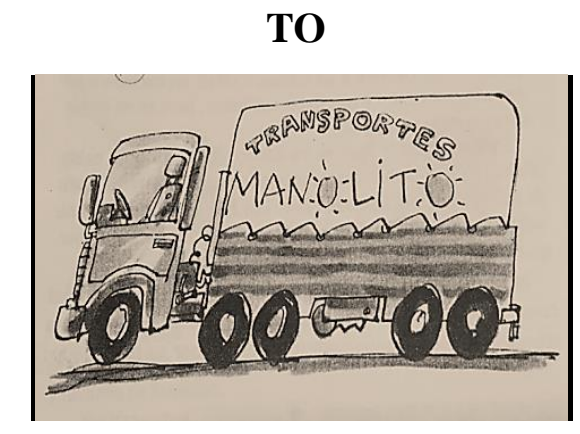

b)

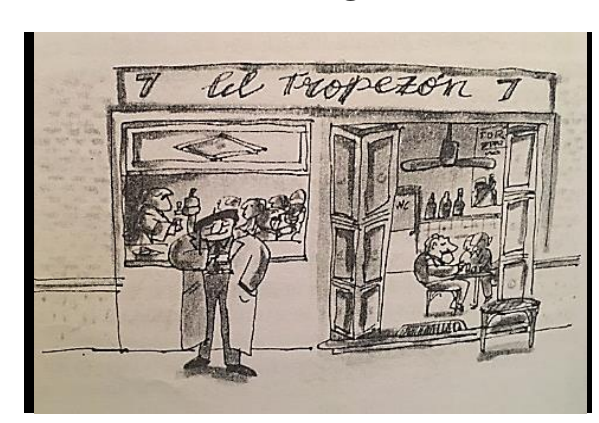

c)

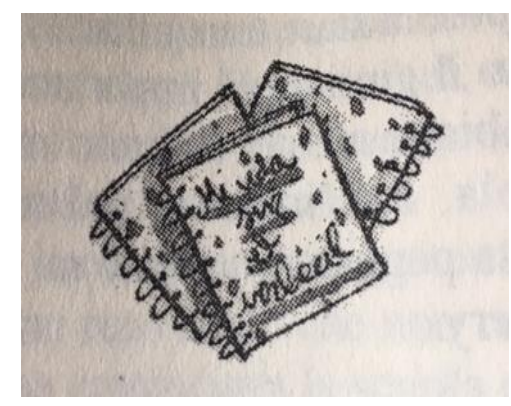

TM

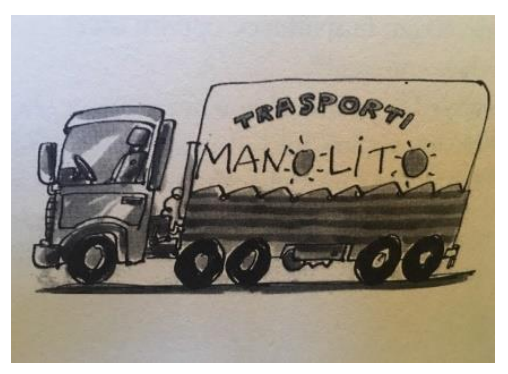

TM

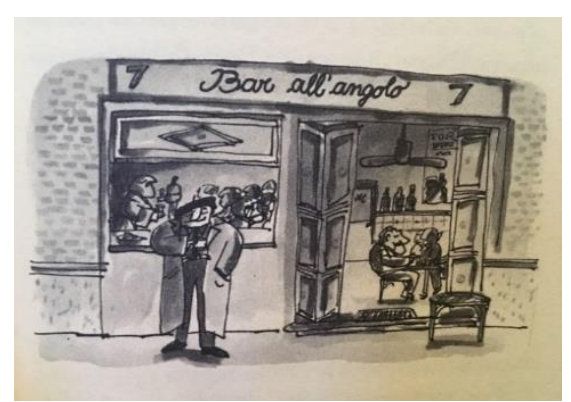

TM

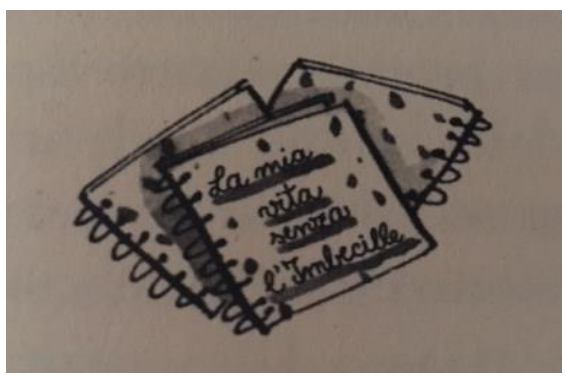

Asimismo, es interesante reflexionar sobre un juego de palabras directamente relacionado con una imagen del libro. En particular, en el capítulo número ocho Manolito y el Orejones se ponen a jugar a las palabras encadenadas y se ve una imagen de los dos niños que están pensando en qué contestar. En el texto español de 2013 la combinación se da entre las palabras monja y jamón, tal y como se ve en el ejemplo (d). Ahora bien, en la traducción italiana se ha optado por la eliminación de las imágenes con la pérdida de la relación entre el contenido lingüístico y el soporte visual existente en el TO. Queda por comprobar si dicha opción traductora ha tenido lugar por cuestiones de tipo práctico (porque la editorial italiana no pudo contar con la colaboración del ilustrador español) o por una decisión personal del traductor. 
d)

TO

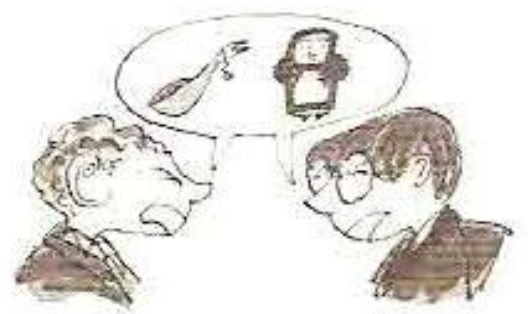

TM

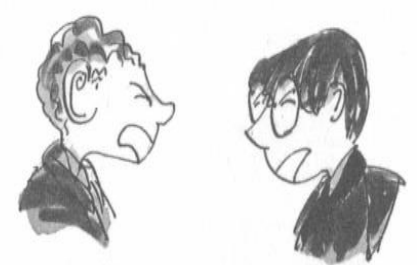

En relación a los títulos de los diez capítulos y a la pequeña imagen que acompaña y a su traducción al italiano, cabe subrayar que, por lo general, las imágenes permanecen inalteradas y se opta por una traducción literal del título en español. Sin embargo, salta a la vista el cambio de ilustración en el capítulo uno y seis, en donde se opta por introducir dos imágenes diferentes respecto al TO. En particular, en el primer capítulo titulado Los de mi barrio se quejan (ejemplo e) se puede ver a Manolito en lugar del podio presente en el TO y en el sexto capítulo (ejemplo f) se omite la imagen de las bragas, que están estrechamente vinculadas al 52 personaje de Susana-bragas-sucias. Consideramos que en este último caso estamos ante un ejemplo de "paternalismo omisor", según explica Lorenzo (2014). En italiano, tal y como sucede en la traducción al inglés estadounidense, al eliminar el elemento escatológico, "no solo se boicotea la doble intencionalidad de la autora, sino que además cambia por completo el sentido del nombre original" (CÁMARA, 2016, p. 28). Como si no bastara, en la versión italiana se quita la imagen de las bragas al comienzo del capítulo pero la alusión visual a esta prenda se mantiene a lo largo del capítulo, lo que produce cierta incoherencia temática, textual y visual. No olvidemos tampoco que el apodo de Susanita se suaviza en Susanna-panni-sporchi (lit. Susana-ropa-sucia) aunque el lector italiano sigue viendo las bragas de la niña a lo largo de las páginas del libro. 
(e)

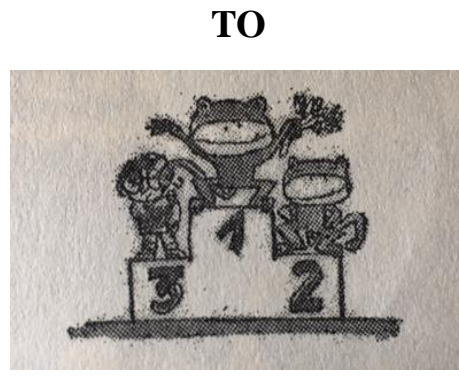

(f)

TO

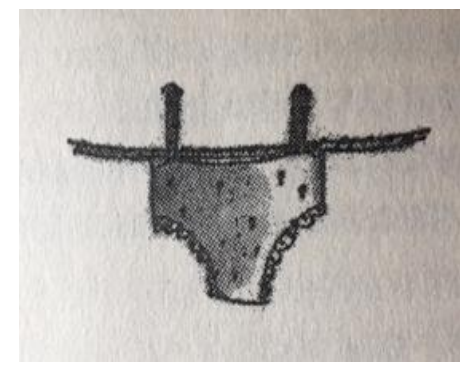

TM

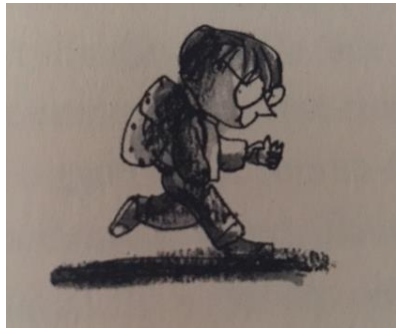

TM

\section{Conclusiones}

A lo largo del presente trabajo hemos reflexionado sobre dos traducciones diferentes de la primera novela de la serie de Manolito Gafotas. En particular, hemos focalizado nuestra atención en los elementos inherentes al andamiaje paratextual de la traducción llevada a cabo en 2014 por la editorial Lapis, precisamente 20 años después de la publicación del original en español. En particular, hemos pasado revista a las características del peritexto y del epitexto editorial de dicha obra y hemos podido constatar, por ejemplo, el cambio de la franja de edad, puesto que en Italia esta novela está recomendada para niños mayores de 9 años, mientras el texto original en español está dirigido a jóvenes de 12 años. Por otra parte, en la cubierta y en la contracubierta destacan múltiples guiños al público adulto con el objetivo no solo de legitimar la valía de la obra, de la autora y del ilustrador, sino también de recibir la aprobación a la lectura por parte de los mayores. No olvidemos el papel determinante que desempeñan los adultos en el ámbito de la LIJ en su calidad de padres, tutores, maestros y pedagogos, entre otros. En cuanto al tratamiento traductológico de las ilustraciones, hemos podido notar que se respeta, por lo general, la coherencia entre texto e imagen, aunque aflora cierta censura temática que se manifiesta también a través de la eliminación de ciertas ilustraciones. Asimismo, en la versión italiana de 2014 se ha optado por la eliminación del soporte visual inherente a un juego de palabras del TO, lo que supone una pérdida de tipo semántico al no poder relacionar el contenido lingüístico con el componente visual. Sin lugar a dudas, esta solución no es la más 
satisfactoria, ya que se hubiera podido encontrar una traducción más creativa, aunque no sabemos si se ha tratado de una falta de ingenio del traductor o de la no colaboración por parte del ilustrador del TO. Lo que sí podemos afirmar es que, por lo general, destaca un afán por presentar un producto editorial que pueda satisfacer las expectativas de los mayores, que son quienes deciden si brindar o no al joven lector la posibilidad de adentrase en el mundo de Manolito y disfrutar de sus peripecias, las de todos los niños de su edad.

\section{REFERENCIAS BIBLIOGRÁFICAS}

ALDERETE DÍEZ, Pilar; HARRINGTON FERNÁNDEZ, Owen. Corrección política y moral en las traducciones de Manolito Gafotas al inglés americano. In: XI Congreso Internacional de la Asociación Nacional de Investigación en Literatura Infantil y Juvenil, Granada, 27-29 sept. 2017.

ÁLVAREZ FERNÁNDEZ, Elisa y SOLIÑO PAZÓ, María Mar. La visión humorística de la realidad cotidiana: Manolito Gafotas y Le Petit Nicolas. In: LABRA, Ana et al. (ed.).

Realismo social y mundos imaginarios, una convivencia para el siglo XXI. Universidad de Alcalá: Servicio de Publicaciones, 2003. p. 59- 70.

54 ARIZA, Mercedes. Manolito por el mundo. Análisis intercultural de las traducciones al inglés, francés, alemán e italiano. Anuario de Investigación en Literatura Infantil y Juvenil, n. 15, p. 211-216, 2017.

BERTINETTI, Paolo. Le traduzioni invecchiano, gli originali no. La Stampa, 13 mar. 2013.

BAZZOCCHI, Gloria; TONIN, Raffaella (ed.). Mi traduci una storia? Riflessione sulla traduzione per l'infanzia e per ragazzi. Bologna: Bup, 2015.

CÁMARA AGUILERA, Elvira. “Traducción y asimetría: Manolito Gafotas y su traducción al inglés como ejemplo de intervencionismo". Anuario de Investigación en Literatura Infantil y Juvenil, n. 14, 2016. p. 23-42.

CHIERICHETTI, Luisa. El lenguaje de Manolito Gafotas. In: CALVI, Maria Vittoria (ed.). Variación linguiística y polifonía en la narrativa española contemporánea. Viareggio: M. Baroni, 2004. p. 69-91.

CHIERICHETTI, Luisa. La traduzione di un romanzo per ragazzi. Manolito il Magnifico. In: CARDINALETTI, Anna; GARZONE, Giuliana (ed.). L'italiano delle traduzioni. Milano: Franco Angeli, 2005. p. 193-210.

CHAUME VARELA, Frederic. La retraducción de textos audiovisuales: razones y repercusiones traductológicas. In: ZARO VERA, Juan Jesús; RUIZ NOGUERA, Francisco (ed.). Retraducir: una nueva mirada: la retraducción de textos literarios y audiovisuales. Málaga: Ediciones Miguel Gómez, 2007. p. 49-63. 
DEMARIA, Cristina; FEDRIGA, Riccardo. Il paratesto. Milano: Edizioni Sylvestre Bonnard, 2001.

DI GIOVANNI, Elena et al. Écrire et traduire pour les enfants. Voix, images et mots/Writing and Translating for Children. Voices, Images and Texts. Bruxelles: Peter Lang, 2010 .

ELEFANTE, Chiara. La traduzione e il paratesto. Bologna: BUP, 2012.

ELEFANTE, Chiara; PEDERZOLI, Roberta. Le parole per dirlo: il tema della morte nel peritesto della letteratura giovanile tradotta. In: BAZZOCCHI, Gloria; TONIN, Raffaella (ed.). Mi traduci una storia? Riflessioni sulla traduzione per l'infanzia e per ragazzi. Bologna: BUP, 2015. p. 57-101.

EXLIBRIS, Regina. Manolito Gafotas es too heavy para EE UU, 2008. En http://blogs.20minutos.es/diariodelibrera/2008/11/11/manolito-gafotas-es-too-heavy-eeuu/. Consultado el: 26 jun. 2019.

GENETTE, Gérard. Seuils. Paris: Point, 1987.

GIL-BARDAJÍ, Ana et al. Translation peripheries: paratextual elements in translation. Bern: Peter Lang, 2012.

KLINGBERG, Göte. Children's fiction in the hands of the translators. Lund: Bloms Boktryckeri Ab, 1986.

LEFEBVRE, Benjamin. Textual Transformations in Children's Literature: Adaptations, Translations, Reconsiderations. New York: Routledge, 2013.

LINDO, Elvira. Manolito Gafotas. Barcelona: Alfaguara, 1994.

LINDO, Elvira. Manolito Quattrocchi. Trad. Fiammetta Biancatelli. Milano: Mondadori, 1999.

LINDO, Elvira. Manolito Gafotas. Barcelona: Seix Barral, 2013.

LINDO, Elvira. Manolito Quattrocchi- Ecco Manolito. Trad. Luisa Mattia. Roma: Lapis, 2014.

LORENZO GARCÍA, Lourdes. Espacios prohibidos y su traducción: Mummy never told me/ The Sprog Owner's Manual, de Babette Cole y Scaredy Squirrel, de Mélanie Watt. In: ROIG RECHOU, Blanca et al. (ed.). O álbum na literatura infantil e xuvenil (2000-2010). Vigo: Xerais, 2011. p. 395-411.

LORENZO GARCÍA, Lourdes. Paternalismo traductor en las traducciones del género infantil y juvenil. TRANS, Revista de Traducción, n. 18, p. 35-48, 2014.

LORENZO GARCÍA, Lourdes; PEREIRA RODRÍGUEZ, Ana María. Avoas bébedas rehabilitadas na traducción: A manipulación do texto orixinal para adecuarse ás características 
do polisistema receptor. In: RUZICKA, Veljka et al. (ed.). Literatura infantil y juvenil: tendencias actuales en investigación. Vigo: Universidad de Vigo, 2000, p. 199-209.

MARCELO WIRNITZER, Gisela. Manolito en inglés. In: PÉREZ VICENTE, Nuria et al. (ed.). Manolito por el mundo. Análisis intercultural de las traducciones al inglés, francés, alemán e italiano. Sevilla: Benilde, 2016. p. 31-79.

MATTIA, Luisa. Intervista a Luisa Mattia. Radio Città del Capo, 2014. En http://manolitoquattrocchi.blogspot.it/2014/07/intervista-luisa-mattia-radio-citta-del.html. Consultado el: 26 jun. de 2019.

MÉNDEZ GONZÁLEZ, Ramón. Paratraducción de la pareja texto/imagen: mutilación y manipulación de paratextos lingüísticos e icónicos. SENDEBAR, n.26, p. 83-98, 2015.

MINARDI, Sabina. L'eroe delle piccole cose. 2014. En:

http://bookmarks.blogautore.espresso.repubblica.it/2014/04/07/leroe-delle-piccole-cose/. Consultado el: 26 jun. de 2019.

OITTINEN, Ritta. Translating for children. New York: Garland, 2000.

OITTINEN, Ritta. Change and renewal: translating the visual in picture books. In: PASCUA, Isabel et al. (ed.). Traducción y Literatura Infantil. Las Palmas de Gran Canaria:

56 Universidad de Las Palmas, 2003. p. 11-24.

OITTINEN, Ritta. Traducir para niños. Las Palmas de Gran Canaria: Servicio de Publicaciones de la Universidad de Las Palmas de Gran Canaria, 2005.

OITTINEN, Ritta. Revoicing characters. In: DI GIOVANNI, Elena et al. (ed.). Écrire et traduire pour les enfants. Voix, images et mots/Writing and Translating for Children. Voices, Images and Texts. Bruxelles: Peter Lang, 2010. p. 149-159.

PARUOLO, Elena. Brave New Worlds. Old and New Classics of Children's Literatures. Bruxelles: Peter Lang, 2011.

PASCUA, Isabel et al. (ed.). Traducción y Literatura Infantil. Las Palmas de Gran Canaria: Universidad de Las Palmas de Gran Canaria, 2003.

PEDERZOLI, Roberta. La traduction de la littérature d'enfance et de jeunesse et le dilemme du destinataire. Frankfurt am MaIn: Peter Lang, 2012.

PÉREZ DÍEZ, María del Carmen. Tú a Carabanchel (alto) y yo a Hogwarts: posible convivencia de realismo y fantasía en el siglo XXI. In: LABRA, Ana et al. (ed.). Realismo social y mundos imaginarios, una convivencia para el siglo XXI. Universidad de Alcalá: Servicio de Publicaciones, 2003. p. 465-475.

PÉREZ VICENTE, Nuria. El traductor no es invisible: las referencias culturales en Manolito Gafotas y su traducción al italiano. In: BAZZOCCHI, Gloria; TONIN, Raffaella (ed.). Mi traduci una storia? Riflessione sulla traduzione per l'infanzia e per ragazzi. Bologna: Bup, 2015. p. 153-178. 
PÉREZ VICENTE, Nuria. Manolito en italiano. In: PÉREZ VICENTE, Nuria et al. (ed.). Manolito por el mundo. Análisis intercultural de las traducciones al inglés, francés, alemán e italiano. Sevilla: Benilde, 2016. p. 181-231.

PÉREZ VICENTE, Nuria et al. (ed.). Manolito por el mundo. Análisis intercultural de las traducciones al inglés, francés, alemán e italiano. Sevilla: Benilde, 2016.

RUZICKA, Veljka. Diálogos intertextuales: Pocahontas. Estudios de literatura infantil y juvenil alemana e inglesa: trasvases semióticos. Frankfurt am MeIn: Peter Lang, 2008.

RUZICKA, Veljka. Diálogos intertextuales: Bambi. Estudios de literatura infantil y juvenil alemana e inglesa: trasvases semióticos. Frankfurt am MeIn: Peter Lang, 2009.

RUZICKA, Veljka; LORENZO GARCÍA, Lourdes. Estudios críticos de traducción de literatura infantil y juvenil. Análisis de las traducciones de obras inglesas y alemanas a las cuatro lenguas oficiales en España. Tomo I (A. Conan Doyle / Ch. Nöstlinger). Oviedo: Septem Ediciones, 2003.

SICILIANO, Thais. Le traduzioni invecchiano. 2013. En: https://diariodiunatraduttrice.wordpress.com/2013/03/21/le-traduzioni-invecchiano/ Consultado el: 26 jun. de 2019.

VALERO CUADRA, Pino. Manolito en alemán. In: PÉREZ VICENTE, N. et al (ed.). Manolito por el mundo. Análisis intercultural de las traducciones al inglés, francés, alemán e italiano. Sevilla: Benilde, 2016, p. 133-180.

WALL, Barbara. The Narrator's Voice: The Dilemma of Children's Fiction. Hampshire \& London: Macmillan, 1991.

YUSTE FRÍAS, José. Para-traducir libros infantís. Viceversa. Revista galega de tradución, 13, p. 135-170, 2007.

YUSTE FRÍAS, José. Paratextual Elements in Translation: Paratranslating Titles in Children's Literature. In: GIL-BARDAJÍ, Ana et al. (ed.). Translation Peripheries. Paratextual Elements in Translation. Berna: Peter Lang, p. 117-134, 2012.

ZARO VERA, Juan Jesús; RUIZ NOGUERA, Francisco. Retraducir: una nueva mirada: la retraducción de textos literarios y audiovisuales. Málaga: Ediciones Miguel Gómez, 2007.

\footnotetext{
* Mercedes ARIZA - Doctora en Lingüística por la Universidad de Vigo. Licenciada en Traducción e Interpretación por la Universidad de Bolonia (Italia). Profesora de traducción español e italiano en la Facultad de traducción de la Fundación Unicampus San Pellegrino. Misano Adriatico, Rimini, Italia.

Página académica: http://www.mercedesariza.com/

ORCID: https://orcid.org/0000-0002-3699-9229

E-mail: mercedes.ariza@ fusp.it

${ }^{1}$ Este certamen, que se celebra cada año en el mes de abril en la ciudad de Bolonia (Italia), cataliza la atención del público europeo e internacional y es un referente en el ámbito de la LIJ. Precisamente, en la edición de 2013, entre los invitados extranjeros, destacó la participación de ANILIJ. Para el programa detallado del evento, consúltese: http://www.bookfair.bolognafiere.it/
} 
${ }^{2}$ La retraducción de 2014 se enmarca en un proyecto editorial más amplio, puesto que la editorial romana Lapis, especializada en LIJ, está volviendo a publicar toda la serie.

${ }^{3}$ Para un análisis pormenorizado de la primera traducción de Mondadori de 1999 remitimos al provechoso y reciente análisis intercultural llevado a cabo sobre las traducciones de Manolito Gafotas al inglés, francés, alemán e italiano (PÉREZ VICENTE et al., 2016). A su vez resultan interesantes los trabajos de Chierichetti $(2004,2005)$ y Pérez Vicente $(2015,2016)$.

${ }^{4}$ Entres sus obras, recordamos: L'elefante del Faraone. All'ombra delle piramidi (con Janna Carioli, 2014), La freccia d'oro. All'ombra delle piramidi (con Janna Carioli, 2014), Tante storie di gru, trattori e caterpillar (2014).

${ }^{5}$ Dichas consideraciones se pueden aplicar también en el ámbito audiovisual, donde se remite a los conceptos de "paratexto audiovisual" y de "paratraducción audiovisual" (YUSTE, 2011, 2012). Efectivamente, según recuerda este autor, las cubiertas de los estuches de los DVD y los carteles de la película, por ejemplo, "constituyen un espacio de auténtica transacción comercial donde la distribuidora se juega el todo por el todo a la hora de publicitar la producción audiovisual o multimedia que quiere vender" (YUSTE, 2011, p. 67). Por estas razones resulta primordial para el traductor comprehender la información icónica y verbal presente en estos textos así como el uso del color y el tipo de composición utilizado.

${ }^{6}$ Destaca el fenómeno de la "purificación" (KLINGBERG, 1986), esto es, un proteccionismo ilimitado donde no encuentran cabida temas impronunciables como la muerte, los malos tratos, el sexo, la excreción y la violencia. Al respecto, es sumamente interesante analizar el carácter internacional de la censura temática en la LIJ, tal y como postula Oittinen (2005, p. 113). Por su parte, según Lorenzo (2014), este tipo de proteccionismo encaja en el 'paternalismo omisor'.

${ }^{7}$ También podría decirse lo contrario; si un adulto lee un libro para niños, este es también un libro para adultos. Por su parte, Paruolo (2011, p. 12) reflexiona sobre la llamada "crossover fiction", es decir, novelas como Alice's Adventures in Wonderland (1865), Le avventure di Pinocchio (1883) y Le Petit Prince (1943) que fueron concebidas exclusivamente para niños y que más tarde suscitaron el interés del público adulto.

${ }^{8}$ En nuestro estudio usaremos la sigla TO para referirnos al texto original editado por Seix Barral (2013), mientras TM para el texto traducido en italiano por Lapis (2014). 